\title{
Arterial stiffness in adult patients after Fontan procedure
}

\author{
Lidia Tomkiewicz-Pajak ${ }^{1 *}$, Hanna Dziedzic-Oleksy ${ }^{1}$, Jacek Pajak², Maria Olszowska' ${ }^{1}$, Jacek Kolcz ${ }^{3}$, Monika Komar ${ }^{1}$ and \\ Piotr Podolec ${ }^{1}$
}

\begin{abstract}
Objectives: Increased arterial stiffness is a risk factor of atherosclerosis and cardio-vascular complications. The aim of the study was to determine whether peripheral vascular function might be an early marker of impaired health status in patients with a single ventricle after Fontan procedure.

Methods and results: Twenty five consecutive adults (11 women and 14 men) aged $24.7 \pm 6.2$ years after the Fontan procedure and 25 sex, age and BMI match healthy volunteers underwent physical examination, blood analysis, transthoracic echocardiography and noninvasive assessment of aortic stiffness. Augmented pressure and Augmentation Index (Alx) were both significantly elevated in Fontan when compared to the controls $(6,08 \pm 0,7$ vs. $2,0 \pm 3,7 ; p=0.002$ and $17,01 \pm 3,3$ vs. $6,05 \pm 11 ; p<0.001$, respectively). There were no differences in pulse wave velocity (PWV), mean blood pressure (BP), brachial pulse pressure (PP), central: systolic BP, diastolic BP and PP. In Fontan group we find negative correlation between PWV and SatO2 $(r=-0.68 ; p=0.04)$ and positive correlation with WBC (0.72; $p=0.72 ; p=0.013)$, INR $(0.81 ; p=0.008)$, TNFa $(r=0.45 ; p=0.04)$, and postoperative time $(r=0.77$; $p=0.02)$. Alx correlates positively only with age at surgery $(r=0.45 ; p=0.04)$. Bilirubin level correlates positively with brachial PP $(r=0.71 ; p=0.02)$ and central PP $(r=0.68 ; p=0.03)$.

The multivariate model showed that SatO2 $(\beta=-0.44, p=0.04)$ was the only independent predictor of PWV $\left(R^{2}=0.32, p=0.03\right)$.

Conclusion: Adult Fontan patients have an increased arterial stiffness assessed by a noninvasive technique. Low arterial oxygen saturation postoperative time, age at surgery, white blood cells, TNFa and bilirubin level are associated with arterial stiffening in these patients. The combination of blood parameters of the hepatic function and noninvasive measurements of arterial stiffness could be helpful in comprehensive care of patients with Fontan circulation.
\end{abstract}

Keywords: Adult, Fontan patients, Arterial stiffness

\section{Introduction}

Non-invasive measurement of vascular parameters is increasingly used to assess the risk of cardiovascular disease. It is considered that the loss of elasticity of the walls of the arteries, especially the aorta is a marker of the early changes that may lead to the development of atherosclerosis and its following complications (eg, hypertension, stroke, myocardial infarction) in healthy individuals [1]. Increase in arterial stiffness was proven to be caused by several factors such as age, hypertension, hypercholesterolemia, diabetes, and

\footnotetext{
* Correspondence: Itom@wp.pl

${ }^{1}$ Institute of Cardiology, Jagiellonian University Medical College and John

Paul II Hospital, 80 Pradnicka St., 31-202 Krakow, Poland

Full list of author information is available at the end of the article
}

smoking [2-5]. In the detection of early growth of the aortic wall stiffness pulse wave velocity (PWV) and/or augmentation index (AIx) are commonly used [6].

Fontan operation is a widely used method of treatment of patients with single ventricle. The main goal of this procedure is the separation of the pulmonary and systemic circulation. The treatment is multistage and it results in the absence of subpulmonary ventricle. The blood flow through the lungs is effected due to the pressure gradient between the systemic veins and the left atrium and has non-pulsatile character $[7,8]$.

A vast majority of the patients born with a functional single ventricle, who underwent Fontan surgery in early childhood, survive over 20 years [9]. The longer the time 
since the surgery, the more frequent remote complications are noted $[8,9]$. Thus patients are at high risk of mortality and morbidity. The development of impaired functional health status is caused by reduced cardiac output, increased systemic vascular resistance, ventricular dysfunction, arrhythmia, and heart failure [7-10].

The present study was designed to evaluate the usefulness of the noninvasive measurement of arterial stiffness to determine whether peripheral vascular function might be an early marker of impaired health status in patients with a single ventricle after Fontan procedure. We also evaluated the impact of endothelial dysfunction and inflammation on parameters of arterial stiffness.

\section{Material and methods}

\section{Study population}

The patients were recruited consecutively at the John Paul II Hospital in Krakow and enrolled into the study if they had had the Fontan operation, were $\geq 18$ years old, and were clinically stable for at least 3 months before the study.

The patients underwent physical examination, blood analysis, transthoracic echocardiography and noninvasive assessment of aortic stiffness. Medical histories were taken and they included demographic, anatomic data, previous interventions and medical therapy. The exclusion criteria were: arrhythmia, any acute illness, cancer, diabetes mellitus, hypertension, acute vascular event, alcohol abuse and pregnancy.

Healthy subjects were not on any medication and had no history of cardiovascular or cerebrovascular disease.

The institutional ethics committee approved the study protocol. All the participants signed informed consent before enrolling into the study.

\section{Arterial stiffness}

Assessment of the central hemodynamic data and aortic stiffness was performed by non-invasive examination of the peripheral arteries. Measurements were performed after 8 hours fasting, before medications, in the supine position, in a quiet room, with an air temperature of $22 \pm 1^{\circ} \mathrm{C}$ [6]. Shortly before the test arterial blood pressure (BP) and heart rate were measured with use of an automatic sphygmomanometer OMRON M6. Tests were performed by applanation tonometry by SphygmoCor * (ATCOR Medical, Sidney, Australia). In order to measure PWV the applanation tonometer was applied at first to the common carotid artery, then to the femoral. The measurements were performed independently of each other but with respect electrocardiography (ECG) registered at the same time.

Central: systolic BP, diastolic BP, pulse pressure (PP), augmented pressure (AP) and augmetation Index (AIx) were obtained during the course of at least 12 seconds registration of the pulse wave graph at the radial artery and calculated by a validated generalized transfer function.

AP is a parameter that determines the difference between the peak of the reflected wave from the periphery (P2) and the peak of the wave generated by the contraction of the left ventricle (P1) (AP = P2 - P1 [mmHg]). $\mathrm{AP}$ describes the increase or decrease in the amount of pulse wave in the ascending aorta in relation to strengthening it by the wave returning from the periphery to the ascending aorta (Figure 1).

AIx is expressed as the ratio of the augmented pressure (AP) and PP in the aorta. (AIx = AP/PP [\%]), and speaks of the percentage change (increase or decrease) of the pressure in the aorta (pulse wave height) under the influence of the peripheral wave and it is dependent on the duration of the cardiac cycle, PWV in the vessels and the amplitude of the reflected wave. Because the value of AIx is influenced by heart rate, AIx was standardized for the heart rate of $75 / \mathrm{min}$ [11].

Single ventricle ejection fraction (SVEF) was assessed by echocardiography (Vivid 7 GE Medical System, USA) using a Simpson method. Oxygen saturation (SatO2) was measured noninvasively by pulse oximeter in room air

\section{Laboratory measurements}

Blood samples from a peripheral vein were drawn into tubes. All blood samples were obtained in the morning after an overnight fast. In patients using warfin, blood was drawn at least 5 days after drug withdrawal. Plasma levels of white blood cells (WBC), platelet count, red blood cells (RBC), hematocrit (HCT), hemoglobin $(\mathrm{Hg})$, total protein, alanine aminotransferase (ALT), C-reactive protein (CRP), creatinine, bilirubin, gamma glutamylo transpeptidaza (GGTP) international normalized ratio (INR), Nterminal pro-B-type natriuretic peptide (NT-pro-BNP) were assayed by routine laboratory techniques.

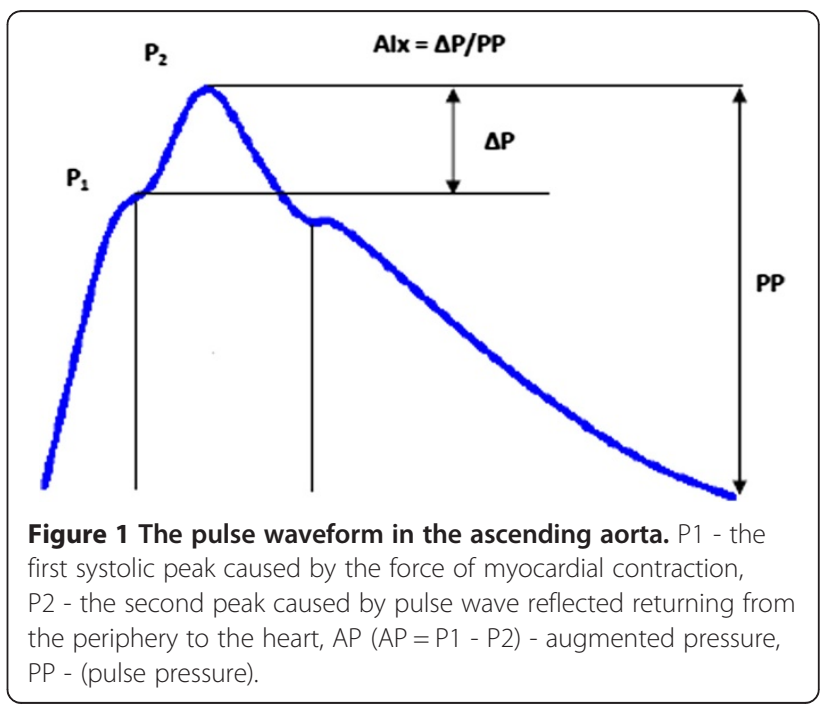


Endothelin-1 level and tumor necrosis factor-alfa $(\mathrm{TNF} \alpha)$ were determined by the ELISA method (R\&D Systems).

\section{Statistical analysis}

Continuous variables are expressed as mean \pm SD. Categorical variables are described as counts and percentages. Patients after Fontan operation and controls were compared with the Mann Whitney U-test for the continuous variables and with the chi square test for categorical variables. Correlations between the individual parameters were calculated using the Spearman rank test. Factors that determine PWV were analyzed using multiple logistic regression. A p-value $<0.05$ was considered statistically significant. The statistical analyses were performed with the PQ Stat version 1.4.2.324 software.

\section{Results}

\section{Group characteristics}

Of 35 patients who were assessed for eligibility, 10 subjects were excluded due to: age below 18 years of life $(n=1)$, lack of informed consent $(n=3)$, and arrhythmias $(n=6)$. The study population consisted of: 25 consecutive adults (11 women and 14 men) aged $24.7 \pm 6.2$ years who underwent the Fontan procedure in their childhood and 25 sex, age and BMI match healthy volunteers. The dominant cardiac malformation were: tricuspid atresia 12 (48\%), pulmonary atresia with ventricular septal defect and transposition of great arteries 8 (32\%), double outlet right ventricle with hypoplasia of left ventricle $2(8 \%)$, double inlet left ventricle $3(12 \%)$. Modification of the Fontan operation included direct right atrium-pulmonary artery connection in $2(8 \%)$ patients and total cavopulmonary connection (TCPC) by means of intraatrial lateral tunnel in the remaining $23(92 \%)$ patients. The mean age at Fontan procedure was $4.6 \pm 3.3$ years. The mean follow-up time was $20.1 \pm 5.2$ years. The patients were in NYHA class I 5 (20\%), NYHA II 18 (72\%) and NYHA III 2 (8\%). Six (24\%) patients were treated with warfarin, 1 (4\%) with enoksaparin, $15(60 \%)$ with aspirin and $3(12 \%)$ were taking inhibitor of angiotensin in a small doses. On the day of examination the patients did not take any medication.

The Fontan patients had lower SVEF (51.6 \pm 5.4 vs. $69.3 \pm 1.6 \%$; $\mathrm{p}<0.001$, SatO2 (88.5 \pm 6.8 vs. $96.9 \pm 1.6 \%$, $\mathrm{p}<0.001)$ and there were no differences in SBP, DBP, HR. Study population characteristic is shown in Table 1.

In Fontan group we also find significant higher RBC $\left(6.2 \pm 2.5\right.$ vs. $\left.4.8 \pm 0.510^{9} / \mu \mathrm{l} ; \mathrm{p}<0.001\right), \mathrm{Hg} \quad(16.8 \pm$ 1.4 vs. $14.1 \pm 1.3 \mathrm{~g} / \mathrm{dl} ; \mathrm{p}<0.001)$, HCT $(49.1 \pm 3.3$ vs. $42.2 \pm 3.3 \% ; \quad \mathrm{p}<0.001), \quad$ GGTP $(87.3 \pm 50.3$ vs. $17.8 \pm$ $8.3 \%$; $<0.001)$, ALT $(30.9 \pm 11.9$ vs. $21.3 \pm 6.2 \mathrm{IU} / \mathrm{l} ; \mathrm{p}<$ $0.001)$, bilirubin $(23.7 \pm 16.3$ vs. $8.1 \pm 3.8 \mu \mathrm{mol} / \mathrm{l} ; \mathrm{p}<$ $0.001), \operatorname{INR}(1.2 \pm 0.2$ vs. $1 \pm 0.1 ; \mathrm{p}<0.001), \mathrm{TNF} \alpha(7.1 \pm$ 1.5 vs. $2.4 \pm 1.2 \mathrm{pg} / \mathrm{ml} ; \mathrm{p}<0.001)$, NT-proBNP $(302.3 \pm$
Table 1 Study population characteristic

\begin{tabular}{llll}
\hline & Fontan $(\mathbf{n}=\mathbf{2 5})$ & Healthy $(\mathbf{n}=\mathbf{2 5})$ & $\mathbf{p}=$ \\
\hline Age, years & $24.7 \pm 6.2$ & $26.9 \pm 3.4$ & 0.14 \\
Sex & $14 \mathrm{M} / 11 \mathrm{~F}$ & $15 \mathrm{M} / 10 \mathrm{~F}$ & 0.4 \\
$\mathrm{BMI}, \mathrm{kg} / \mathrm{m}^{2}$ & $21,7 \pm 2$ & $22,56 \pm 3$ & 0.3 \\
$\mathrm{SBP}, \mathrm{mmHg}$ & $127.2 \pm 13.9$ & $124 \pm 10.6$ & 0.42 \\
$\mathrm{DBP}, \mathrm{mmHg}$ & $79.4 \pm 7.3$ & $77.7 \pm 5.2$ & 0.32 \\
$\mathrm{HR}, \mathrm{BPM}$ & $64.8 \pm 12.6$ & $68.9 \pm 16.2$ & 0.33 \\
SatO2,\% & $88.5 \pm 6.8$ & $96.9 \pm 1.6$ & $<0.001$ \\
SVEF,\% & $51.6 \pm 5.4$ & $69.3 \pm 1.6$ & $<0.001$ \\
\hline
\end{tabular}

BMI-body mass index, SBP-systolic blood pressure, DBP- diastolic blood pressure, HR- heart rate, SatO2 - arterial saturation, SVEF - single ventricle ejection fraction

601.8 vs. $72.2 \pm 45.9 \mathrm{pg} / \mathrm{ml} ; \mathrm{p}<0.001)$, endothelin levels $(2.5 \pm 0.1$ vs. $1.3 \pm 0.05 \mathrm{pg} / \mathrm{ml} ; \mathrm{p}=0.002)$ and significantly lower platelet account (127.8 \pm 33.8 vs. $228.1 \pm$ $\left.50.610^{9} / \mu \mathrm{l} ; \mathrm{p}=<0.001\right)$. There were no differences in WBC, total protein, creatynin and CRP. The results are shown in Table 2.

\section{Arterial stiffness}

Augmented pressure and Augmentation Index were both significantly elevated in Fontan when compared to the controls $(6.08 \pm 0.7$ vs. $2.0 \pm 3.7 ; \mathrm{p}=0.002$ and $17.01 \pm 3.3$ vs. $6.05 \pm 11 ; \mathrm{p}<0.001$, respectively). There were no differences in PWV, Mean BP, brachial PP, Central SBP, Central DBP, Central PP. The results are presented in Table 3.

Table 2 Laboratory characteristics of Fontan patients and controls

\begin{tabular}{|c|c|c|c|}
\hline Variable & Fontan $(n=25)$ & Controls $(n=25)$ & $p$ \\
\hline $\mathrm{WBC}, 10^{3} / \mu \mathrm{l}$ & $5.2 \pm 1.6$ & $5.9 \pm 1.4$ & 0.1 \\
\hline $\mathrm{RBC}, 10^{9} / \mu \mathrm{l}$ & $6.2 \pm 2.5$ & $4.8 \pm 0.5$ & $<0.001$ \\
\hline $\mathrm{Hg}, \mathrm{g} / \mathrm{dl}$ & $16.8 \pm 1.4$ & $14.1 \pm 1.3$ & $<0.001$ \\
\hline $\mathrm{HCT}, \%$ & $49.1 \pm 3.3$ & $42.2 \pm 3.3$ & $p<0.001$ \\
\hline Platelet count, $10^{3} / \mu \mathrm{l}$ & $127.8 \pm 33.8$ & $228.1 \pm 50.6$ & $<0.001$ \\
\hline Total protein, g/dl & $75.9 \pm 4.9$ & $73.9 \pm 2.5$ & 0.08 \\
\hline GGTP, U/L & $87.3 \pm 50.5$ & $17.8 \pm 8.3$ & $<0.001$ \\
\hline $\mathrm{ALT}, \mathrm{IU} / \mathrm{I}$ & $30.9 \pm 11.9$ & $21.3 \pm 6.2$ & $<0.001$ \\
\hline Bilirubin, $\mu \mathrm{mol} / / \mathrm{l}$ & $23.7 \pm 16.3$ & $8.1 \pm 3.8$ & $<0.001$ \\
\hline INR, & $1.2 \pm 0.2$ & $1 \pm 0.1$ & $<0.001$ \\
\hline $\mathrm{TNFa}, \mathrm{pg} / \mathrm{ml}$ & $7.1 \pm 1.5$ & $2.4 \pm 1.2$ & $<0.001$ \\
\hline CRP, mg/l & $2.6 \pm 2.7$ & $1.9 \pm 1.7$ & 0.6 \\
\hline Endthelin-1, pg/ml & $2.5 \pm 0.1$ & $1.3 \pm 0.05$ & 0.002 \\
\hline NTpro-BNP & $302.3 \pm 601.8$ & $72.2 \pm 45.9$ & $<0.001$ \\
\hline
\end{tabular}

WBC- white blood cells, RBC - red blood cells, $\mathrm{Hg}$ - hemoglobin, HCT- hematocrit, GGTP - gammaglutamylo transpeptydaza, ALT - alanine aminotransferase, INR - international normalized ratio, TNFa - tumor necrosis factor alfa, CRP - C-reactive protein, NT-pro-BNP- N-terminal pro-B-type natriuretic peptide. 
Table 3 Arterial stiffness measurements

\begin{tabular}{llll}
\hline & Fontan $(\mathbf{n}=\mathbf{2 5})$ & Healthy $(\mathbf{n}=\mathbf{2 5})$ & $\mathbf{p =}$ \\
\hline PWV $(\mathrm{m} / \mathrm{s})$ & $7,81 \pm 1,0$ & $7,91 \pm 0,8$ & 0.34 \\
AP & $6,08 \pm 0,7$ & $2,0 \pm 3,7$ & 0.002 \\
Alx & $17,01 \pm 3,3$ & $6,05 \pm 11$ & $<0.001$ \\
Mean BP, mm Hg & $94,5 \pm 8,61$ & $92,2 \pm 6,9$ & 0,29 \\
PP brachial, mm Hg & $47,4 \pm 13,8$ & $46,2 \pm 11,5$ & 0,74 \\
Central SBP, mm Hg & $113,4 \pm 12,3$ & $107,9 \pm 9,0$ & 0,07 \\
Central DBP, mm Hg & $80.4 \pm 7,6$ & $78,1 \pm 5,4$ & 0,21 \\
Central PP, mm Hg & $33,0 \pm 10,5$ & $29,8 \pm 6,7$ & 0,19 \\
\hline
\end{tabular}

PVW- Pulse Wave Velocity, AP- Augmented Pressure, Alx- Augmentation Index, $\mathrm{BP}$ - blood pressure, PP- pulse pressure, SBP - systolic blood pressure, DBPdiastolic blood pressure.

In Fontan group we find negative correlation between PWV and SatO2 $(r=-0.68 ; \mathrm{p}=0.04)$ and positive correlation with WBC $(\mathrm{r}=0.72 ; \mathrm{p}=0.72 ; \mathrm{p}=0.013)$, INR $(\mathrm{r}=$ $0.81 ; \mathrm{p}=0.008)$, TNF $\alpha(\mathrm{r}=0.45 ; \mathrm{p}=0.04)$, and postoperative time $(\mathrm{r}=0.77 ; \mathrm{p}=0.02)$. We did not find similar correlation in controls.

Augmentation Index correlates positively only with age of surgery $(r=0.45 ; \mathrm{p}=0.04)$. Bilirubin level correlates positively with $\mathrm{PP}$ brachial $(\mathrm{r}=0.71 ; \mathrm{p}=0.02)$ and Central PP $(\mathrm{r}=0.68 ; \mathrm{p}=0.03)$.

To determine the independent effect of clinical and laboratory variables, the stepwise regression analysis for PWV as a dependent variable was performed. The multivariate model showed that SatO2 $(\beta=-0.44, \mathrm{p}=0.04)$ was the only independent predictor of PWV $\left(R^{2}=0.32\right.$, $\mathrm{p}=0.03)$.

\section{Discussion}

In the present study of arterial stiffness in patients after Fontan procedure, we showed increased Augmentation Index and no difference in Pulse Wave Velocity between Fontan patients and healthy population. In a healthy cardiovascular system, the flexible wall of the aorta increases its volume during the systolic ejection of blood from the left ventricle. This feature prevents excessive increase in systolic blood pressure. Then, in the diastole aortic volume it gradually returns to the original size, ensuring the free flow of blood towards the peripheral vessels. Pulse wave, created in this way, reaches the distal parts of the circulatory system, and reflects back towards the heart, reaching the ascending aorta during the next diastole phase. Its return strengthens the new pulse wave, causes the increase in diastolic blood pressure, and provides adequate perfusion of the coronary arteries [6]. The aorta acts as a conduit and a cushion for pulsate flow of the blood, and any stiffening of its wall results in faster propagation of the blood (i.e., increased PWV). Arterial stiffness represents the load against which the left ventricle must eject its volume.
Arterial stiffness may be evaluated in any part of the arterial system. However, the process of stiffening that occurs in the walls of the aorta is the one of the primary interest [6]. In literature there is evidence that increased arterial stiffness is an independent predictor of morbidity and mortality in patients with cardiovascular diseases as well as in healthy individuals [12-16].

The idea that the biophysical properties of the aorta are abnormal in a population of patients with Fontan circulation has been recently studied by Myers at al [17]. Their research showed that Fontan patients had faster PWV, implying stiffer arteries and abnormal arterial health. They concluded that increased arterial stiffness is an additional factor responsible for the development of late ventricular failure in patients with single ventricles.

Our data are similar to the results of Lambert et al. [18]. The authors not only showed the increased arterial stiffness comparing to healthy controls, but also demonstrated that Fontan patients have increased muscle sympathetic nerve activity and impaired endothelial function too. They postulated that monitoring the development of the increased arterial stiffness along with clinical outcomes may help in delay of the inevitable diastolic dysfunction of the Fontan patients' heart.

The mechanism leading to an increased arterial stiffness in Fontan patients is difficult to define. It was proven that parameters of the arterial stiffness are under the influence of age [17]. The results of our study do not confirm the relationship between abnormal arterial stiffness and patients age. Moreover, we find association between parameters of arterial stiffness and postoperative time in patients with Fontan circulation. There is evidence that majority of complications appear late after Fontan procedure $[8,10]$. We also find association between augmentation index and age at surgery. The results are not surprising, given the fact that before the surgery, chronic cyanosis and volume overloading may contribute to arterial stiffness [7].

Our study demonstrated that arterial oxygen saturation is an important determinant of arterial stiffness in adult Fontan patients. To our knowledge there was no research in this area. However, the problem was discussed in literature concerning patients with sleep-disordered breathing as well as in patients with chronic obstructive pulmonary disease (COPD). The authors $[19,20]$ found that nocturnal O2 desaturation caused by sleep apnea is associated with increased PWV among normotensive and hypertensive individuals. Cinarka et al. [21] not only showed that hypoxemia affects arterial stiffness, but also proved that PWV is faster in patients with severe COPD than in patients with milder forms of this disease.

Previous study showed that arterial oxygen saturation decreased in majority of adult Fontan patients [8]. The reason of this phenomena is multifactorial and may result 
from a progressive impairment of single ventricle function, a rise in pulmonary pressure and right-to-left shunt through an atrial fenestration or venovenous collaterals $[8,9]$. In our study fenestration was an open in $25 \%$ of patients. Wykretowicz et al [22] showed that in adult patients with cyanotic congenital heart diseases arterial stiffness is affected by hematocrit concentration but not SatO2. However, our study did not find such correlation It should be noted that presented patients with cyanotic congenital heart diseases had higher mean hematocrit level (64\%) than our Fontan patients.

Another factor that may affect the biophysical properties of the aorta and therefore influence the wave reflection, arterial pressure augmentation and contribute to central and peripheral vascular dysfunction, is endothelial dysfunction. We find elevated endothelial level in Fontan patients. Jin et al. [23] has shown that the endothelial dysfunction is more prevalent in Fontan patients compared with healthy controls. Also the study of Natarajan et al. [24] which evaluated vascular function in patients with pre-Fontan singleventricle physiology reported an increased endothelin-1 level and decreased flow-mediated dilation.

Our study showed that also inflammation influenced arterial stiffness in adult Fontan patients. We find correlation between PWV and white blood cells and TNF $\alpha$. There is limited data regarding the relationship of inflammation with arterial stiffness in patients with single ventricle. However, previous study demonstrated that increase in systemic inflammation is an independent predictor of future development of hypertension [25]. The increased vascular inflammation may increase vascular fibrosis, cells proliferation, impaired endothelial which lead to increased arterial stiffness [26]. The white blood count is a simple and common test that was also proven to be associated with stiffening of the arterial walls [27]. However all of the studies concerned population with cardiovascular problems such as hypertension, diabetes or coronary artery disease. It has been suggested that an elevated white blood count, even within normal range, is significantly associated with all cause, cardiovascular, and cancer mortality [28]. We believe that this simple test may be useful to determine the entirety condition of the patient with Fontan circulation.

Liver is the organ at great risk after the Fontan operation [29]. Hepatic dysfunction caused by volume overload and low cardiac output may result from a coexistence of passive venous congestion of the liver, hypoxia, or concomitant pulmonary disease [30]. Noninvasive measures of hepatic function include inter alia the measurements of bilirubin, albumin, international normalized ratio. Most patients with congenital heart disease and passive venous congestion of the liver have elevated indirect bilirubin and prolonged international normalized ratio with minimal elevations of the aminotransferases [31]. We have observed the same results in our patients. Moreover, we have demonstrated that these parameters remain in correlation with noninvasive measurement of arterial stiffness. The association of liver disease and increased arterial stiffness and therefore elevated cardiovascular risk has been previously shown in nondiabetic, nonhypertensive individuals [32]. It has been postulated that screening tests that could identify earlier stages of hepatic dysfunction development would be of a great value, especially since currently used tests are relatively insensitive [30]. The combination of blood parameters of the hepatic function and noninvasive measurements of arterial stiffness could be helpful in comprehensive care of patients with Fontan circulation.

\section{Study limitation}

Several limitations of this study should be acknowledged. The study group was small and heterogeneous with regard to type of surgery. Also medication administrated to the Fontan patients is not without an effect on the arterial stiffness. The patients in our study were taking medication such as ACE inhibitors - the drugs that decrease AIx [21]. This may suggest that the actual impact of increased arterial stiffness may be underestimated. However the patients did not take any medication on the day of examination. Moreover, we did not determined single ventricle ejection fraction on magnetic resonance. However, previous studies. demonstrated similar interobserver reproducibility for echocardiographic and cardiac magnetic resonance assesment of single ventricle function. Overall, the cardiac magnetic resonance data were inadequate or incoplite in $30 \%$ of patients in whom the test was performer, predominantly, due to metallic artefacts $[8,33,34]$.

\section{Conclusion}

Adult Fontan patients have an increased arterial stiffness assessed by noninvasive technique. Low arterial oxygen saturation postoperative time, age at surgery and bilirubin level are associated with arterial stiffening in these patients. The combination of blood parameters of the hepatic function and noninvasive measurements of arterial stiffness could be helpful in comprehensive care of patients with Fontan circulation.

\section{Competing interests}

The authors declare that they have no competing interests.

\section{Authors' contributions}

LTP designed the study, collected the data, interpreted the data and drafted the article. HDO participated in the design of the study, collected data and helped to draft the manuscript. JP collected the data and interpreted the data. MO interpreted the data and helped to draft the manuscript. JK collected the data, interpreter the data, MK collected data. PP interpreted the data, helped to draft the manuscript and designed the study. All authors read and approved the final manuscript. 


\section{Acknowledgements}

The study was funded by the Jagiellonian University Medical College.

\section{Author details}

${ }^{1}$ Institute of Cardiology, Jagiellonian University Medical College and John Paul II Hospital, 80 Pradnicka St., 31-202 Krakow, Poland. '2Department of Pediatric Cardiology, Silesian Pediatric Medical Center, Katowice, Poland. ${ }^{3}$ Department of Pediatric Cardiac Surgery, Polish-American Children's Hospital, Krakow, Poland.

Received: 11 March 2014 Accepted: 2 April 2014

Published: 10 April 2014

\section{References}

1. Kopeć G, Podolec M, Dziedzic H, Sobień B: The concept of arterial stiffness in cardiovascular disease prevention. Kardiol Pol 2010, 68:364-368.

2. Kopeć G, Podolec P, Podolec J, Rubis P, Zmudka K, Tracz W: Atherosclerosis progression affects the relationship between endothelial function and aortic stiffness. Atherosclerosis 2009, 204:250-254.

3. Wilkinson IB, Prasad K, Hall IR, Thomas A, MacCallum H, Webb DJ, Frenneaux $M P$, Cockcroft JR: Increased central pulse pressure and augmentation index in subjects with hypercholesterolemia. J Am Coll Cardiol 2002, 39:1005-1011.

4. Chen Y, Huang Y, Li X, Xu M, Bi Y, Zhang Y, Gu W, Ning G: Association of arterial stiffness with $\mathrm{HbA} 1 \mathrm{C}$ in 1,000 type 2 diabetic patients with or without hypertension. Endocrine 2009, 36:262-267.

5. Mahmud A, Feely J: Effect of smoking on arterial stiffness and pulse pressure amplification. Hypertension 2003, 41:183-187.

6. Laurent S, Cockcroft J, Van Bortel L, Boutouyrie P, Giannattasio C, Hayoz D, Pannier B, Vlachopoulos C, Wilkinson I, Struijker-Boudier H: Expert consensus document on arterial stiffness: methodological issues and clinical applications. Eur Heart J 2006, 27:2588-2605.

7. Khairy P, Poirier N, Mercier L: Univentricular heart. Circulation 2007, 115:800-812.

8. Tomkiewicz-Pajak L, Hoffman P, Trojnarska O, Bednarek J, Płazak W, Pajak J, Olszowska M, Komar K, Podolec P: Long term follow-up in adult patients after Fontan operations. Polish J Cardiothorac Surg 2013, 10:357-363.

9. d'Udekem Y, lyengar AJ, Cochrane AD, Grigg LE, Ramsay JM, Wheaton GR, Penny DJ, Brizard CP: The Fontan procedure: contemporary techniques have improved long-term outcomes. Circulation 2007, 116(11Suppl):1157-|164.

10. Kupferschmid JP, Burnett J, Jonas RA, Castaneda AR, Wernovsky G: Fontan operation in five hundred consecutive patients: factors influencing early and late outcome. J Thorac Cardiovasc Surg 1997, 114:376-391.

11. Wilkinson IB, MacCallum H, Flint L, Cockcroft JR, Newby DE, Webb DJ: The influence of heart rate on augmentation index and central arterial pressure in humans. J Physiol 2000, 525 Pt1:263-270.

12. Mitchell GF, Parise H, Benjamin EJ, Larson MG, Keyes MJ, Vita JA, Vasan RS, Levy D: Changes in arterial stiffness and wave reflection with advancing age in healthy men and women: the Framingham heart study. Hypertension 2004, 43:1239-1245.

13. Laurent S, Boutouyrie P, Asmar R, Gautier I, Laloux B, Guize L, Ducimetiere P, Benetos A: Aortic stiffness is an independent predictor of all-cause and cardiovascular mortality in hypertensive patients. Hypertension 2001, 37:1236-1241.

14. Cruickshank K, Riste L, Anderson SG, Wright JS, Dunn G, Gosling RG: Aortic pulse-wave velocity and its relationship to mortality in diabetes and glucose intolerance: an integrated index of vascular function? Circulation 2002, 106:2085-2090.

15. Blacher J, Safar ME, Guerin AP, Pannier B, Marchais SJ, London GM: Aortic pulse wave velocity index and mortality in end-stage renal disease. Kidney Int 2003, 63:1852-1860.

16. Mattace-Raso FU, van der Cammen TJ, Hofman A, van Popele NM, Bos ML, Schalekamp MA, Asmar R, Reneman RS, Hoeks AP, Breteler MM, Witteman $J C$ : Arterial stiffness and risk of coronary heart disease and stroke: the Rotterdam study. Circulation 2006, 113:657-663.

17. Myers KA, Leung MT, Terri Potts M, Potts JE, Sandor GG: Noninvasive assessment of vascular function and hydraulic power and efficiency in pediatric Fotan patients. J Am Soc Echocardiogr 2013, 26:1221-1227.

18. Lambert E, d'Udekem Y, Cheung M, Sari Cl, Inman J, Ahimastos A, Eikelis N, Pathak A, King I, Grigg L, Schlaich M, Lambert G: Sympathetic and vascular dysfunction in adult patients with Fontan circulation. Int J Cardio/ 2013, 167:1333-1338.

19. Korcarz CE, Gepner AD, Peppard PE, Young TB, Stein JH: The effects of sleep-disordered breathing on arterial stiffness are modulated by age. Sleep 2010, 3:1081-1085.

20. Drager LF, Diegues-Silva L, Diniz PM, Bortolotto LA, Pedrosa RP, Couto RB, Marcondes B, Giorgi DM, Lorenzi-Filho G, Krieger EM: Obstructive sleep apnea, masked hypertension, and arterial stiffness in men. Am J Hypertens 2010, 23:249-254.

21. Cinarka H, Kayhan S, Gumus A, Durakoglugil ME, Erdogan T, Ezberci I, Yavuz A, Ozkaya S, Sahin U: Arterial stiffness measured via carotid femoral pulse wave velocity is associated with disease severity in COPD. Respir Care 2014, 59:274-280.

22. Wykretowicz A, Trojnarska O, Guzik P, Katarzyska A: Arterial stiffness in adult patients with cyanotic congenital heart disease. Congenit Heart Dis 2007, 2:134-138.

23. Jin SM, Noh Cl, Bae EJ, Choi JY, Yun YS: Impaired vascular function in patients with Fontan circulation. Int J Cardio/ 2007, 120:211-226.

24. Natarajan S, Heiss C, Yeghiazarians Y, Fineman JR, Teitel DF, Tacy TA: Peripheral arterial function in infants and young children with one-ventricle physiology and hypoxemia. Am J Cardiol 2009, 103:862-866.

25. Jekell A, Malmqvist K, Wallén NH, Mörtsell D, Kahan T: Markers of inflammation, endothelial activation, and arterial stiffness in hypertensive heart disease and the effects of treatment: results from the SILVHIA study. J Cardiovasc Pharmacol 2013, 62:559-566.

26. Park S, Lokatta EG: Role of inflammation in the pathogenesis of arterial stiffness. Yonsei Med J 2012, 53:258-261.

27. Lee YJ, Lee JW, Kim JK, Lee JH, Kim JH, Kwon KY, Lee HR, Lee DC, Shim JY: Elevated white blood cell count is associated with arterial stiffness. Nutr Metab Cardiovasc Dis 2009, 19:3-7.

28. Jee SH, Park JY, Kim HS, Lee TY, Samet JM: White blood cell count and risk for all-cause, cardiovascular, and cancer mortality in a cohort of Koreans. Am J Epidemiol 2005, 162:1062-1069.

29. Rychik J, Veldtman G, Rand E, Russo P, Rome JJ, Krok K, Goldberg DJ, Cahill AM, Wells RG: The precarious state of the liver after a Fontan operation: summary of a multidisciplinary symposium. Pediatr Cardiol 2012, 33:1001-1012.

30. Asrani S, Asrani N, Freese D, Phillips S, Warnes C, Heimbach J, Kamath P: Congenital heart disease and the liver. Hepatology 2012, 56:1160-1169.

31. Kim BJ, Kim NH, Kim BS, Kang JH: The association between nonalcoholic fatty liver disease, metabolic syndrome and arterial stiffness in nondiabetic, nonhypertensive individuals. Cardiology 2012, 123:54-61.

32. Shimizu M, Kario K: Role of the augmentation index in hypertension. Ther Adv Cardiovasc Dis 2008, 2:25-35.

33. Margossian R, Schwartz ML, Prakash A, Wruck L, Colan SD, Atz AM, Bradley TJ, Fogel MA, Hurwitz LM, Marcus E, Powell AJ, Printz BF, Puchalski MD, Rychik J, Shirali G, Williams R, Yoo SJ, Geva T, Pediatric Heart Network Investigators: Comparison of echocardiographic and cardiac magnetic resonance imaging measurements of functional single ventricular volumes, mass, and ejection fraction (from the Pediatric Heart Network Fontan Cross-Sectional Study. Am J Cardiol 2009, 104:419-428.

34. Garg R, Powell AJ, Sena L, Marshall AC, Geva T: Effects of metallic implants on magnetic resonance imaging evaluation of Fontan palliation. Am J Cardiol 2005, 95:688-691.

\section{doi:10.1186/1476-7120-12-15}

Cite this article as: Tomkiewicz-Pajak et al:: Arterial stiffness in adult patients after Fontan procedure. Cardiovascular Ultrasound 2014 12:15. 